\title{
Synthesis and Antifungal Activities of Cinnamaldehyde Derivatives against Penicillium digitatum Causing Citrus Green Mold
}

\author{
Zengyu Gan $\mathbb{D}^{1},{ }^{1}$ Jianping Huang, ${ }^{2}$ Jinyin Chen $\mathbb{D}^{1,},{ }^{1,3}$ Muhammad Farrukh Nisar $\mathbb{D}^{1,}, 4,5$ \\ and Wenwen $\mathbf{Q i}^{1}$ \\ ${ }^{1}$ Collaborative Innovation Center of Post-Harvest Key Technology and Quality Safety of Fruits and Vegetables in Jiangxi Province, \\ Jiangxi Key Laboratory for Postharvest Technology and Non-destructive Testing of Fruits \& Vegetables, \\ Jiangxi Agricultural University, Nanchang 330045, China \\ ${ }^{2}$ College of Science, Jiangxi Agricultural University, Nanchang 330045, China \\ ${ }^{3}$ College of Materials and Chemical Engineering, Pingxiang University, Pingxiang, Jiangxi 337055, China \\ ${ }^{4}$ Key Laboratory of Crop Physiology Ecology and Genetic Breeding, Ministry of Education, Jiangxi Agricultural University, \\ Nanchang, Jiangxi, China \\ ${ }^{5}$ Department of Physiology and Biochemistry, Cholistan University of Veterinary and Animal Sciences (CUVAS), \\ Bahawalpur, Pakistan \\ Correspondence should be addressed to Jinyin Chen; jinyinchen@126.com
}

Received 2 August 2020; Revised 18 August 2020; Accepted 21 September 2020; Published 15 October 2020

Academic Editor: Kannan R. R. Rengasamy

Copyright (c) 2020 Zengyu Gan et al. This is an open access article distributed under the Creative Commons Attribution License, which permits unrestricted use, distribution, and reproduction in any medium, provided the original work is properly cited.

Penicillium digitatum (green mold) is pathogenic fungi and causes citrus fruit postharvest rotting that leads to huge economic losses across the world. The current study was aimed to develop a new derivative of cinnamaldehyde (4-methoxycinnamaldehyde) through the cross-hydroxyaldehyde condensation method with benzaldehyde substituted by a benzene ring under the catalysis of alkaline reagent and, moreover, to test their antifungal potential against $P$. digitatum, the major citrus fruit rotting fungi. Multiple derivatives of cinnamaldehyde viz. 4-nitro CA, 4-chloro CA, 4-bromo CA, 4-methyl CA, 4-methoxy CA, and 2,4-dimethoxy CA were synthesized in the current study whereas the 4-methoxy CA showed highest antifungal actions for citrus fruit postharvest rotting fungi $P$. digitatum. Moreover, 4-methoxy CA was found to reduce the spore germination and growth by damaging the fungal cell membrane, as well as declined the levels of reducing sugars.

\section{Introduction}

Many plant pathogenic fungal strains are known to cause huge economic losses because of the reduction in yield and production throughout the world. Green mold (Penicillium digitatum) is an important pathogen causing postharvest losses at citrus fruits. Citrus fruit is a commercial crop grown across the globe and is highly consumed due to its high nutritional value and health benefits [1]. During postharvest storage, multiple biotic and abiotic factors may lead to the decay at citrus fruits mainly caused by the green mold ( $P$. digitatum) causing approximately $90 \%$ of postharvest yield loss [2-4]. At present, various physical and chemical treatment methods are in practice to control the postharvest green mold. Such treatment methods include the application of certain synthetic and natural fungicides, where the synthetic fungicides are considered as the standard treatment method for controlling citrus postharvest green mold but have certain environmental and health issues [5-7].

Due to increasing health concerns, synthetic fungicides are being replaced gradually by the natural phytochemicals bearing strong antifungal potential in recent years. Since the last decade, the researchers are focusing on the use of some alternatives of the synthetic fungicides by natural plants or 
their phytochemical derivatives, such as cinnamaldehyde for controlling of citrus postharvest diseases [8-10]. Cinnamaldehyde along with its various derivatives has been well classified as potential antifungal agents [11, 12]. Furthermore, excessive use of synthetic chemicals for controlling fungal born pathologies is truly a challenging job, because of the increase in the fungi resistance to chemicals, hence leading to explore novel antifungal chemicals. Cinnamaldehyde is studied extensively and reported to inhibit the growth of various pathologic bacterial strains $[13,14]$ and many fungi [15] through acting on the ATPase activities, biosynthesis on the cell walls, and modulation in the membranous structures [16-18].

Cinnamaldehyde (CA) is a major component in the cinnamon essential oils extracted from the cinnamon tree bark [19]. Different from many other related natural compounds, cinnamaldehyde has been used as a potential antifungal agent, but its volatile nature and pungent smell limit its application. Thus, this led the scientists to modify cinnamaldehyde into stable but acceptable derivatives [20-22]. Cinnamaldehyde was complexed with Schiff bases (N,N,bis( $p$-methoxycinnamaldehyde) ethylenediamine) and found that the resulting complex has better biological activities [23]. Moreover, $\alpha$-substituted cinnamaldehyde derivatives ( $\alpha$-bromocinnamaldehyde, $\alpha$-chlorocinnamaldehyde, and $\alpha$-methylcinnamaldehyde) have strong antityrosinase activity [24]. In another study, $\alpha$-bromocinnamaldehyde showed antifungal properties against many of the household items and gadgets was reported to disrupt the metabolic activities of the fungal cells [25]. 2'-Benzoyloxycinnamaldehyde has known to affect the growth of fungal hyphae by reducing the expression of chitin synthases of many of the human pathogenic fungi [26], where similar reduction in fungal growth has also seen by two more similar derivatives (2-chloro- and 2-bromocinnamaldehyde). A variety of amino acid (AA) composed derivatives of CA were successfully developed and found to have potential antifungal agents, particularly for Saccharomyces cerevisiae [27]. Different strains of Candida were also tested for the effective antifungal potential of the o-methoxy CA, and a marked and clear reduction in the growth of various Candida strains was mainly targeting to membranous $\mathrm{H}^{+}$-ATPase by the CA [28]. Moreover, $\alpha$-bromo $\mathrm{CA}$ and p-nitro- $\alpha$-bromo CA are quiet effective against the proliferation of Candida albicans and Trichophyton mentagrophytes [29]. N-(cinnamyl) chitosan derivatives were also reported to have antifungal potential against many fungal strains viz. Botrytis cinerea, Alternaria alternata, Fusarium oxysporum (F. oxysporum), F. solani, Pythium debaryanum, Botryodiplodia theobromae, and Phytophthora infestans [30].

Keeping in view the diverse physiological effects of cinnamaldehyde and its derivatives, herein we attempted to develop a new derivative of cinnamaldehyde (4-methoxycinnamaldehyde) and to test its antifungal potential against Penicillium digitatum, the major citrus fruit rotting fungi. The current study also aimed to understand and elucidate the basic mechanism of action of 4-methoxy CA on the growth of the green mold, germination of spores, and permeability of fungal cell membranes.

\section{Materials and Methods}

2.1. The Pathogenic Fungal Strain and Culture Medium. The isolates of Penicillium digitatum inoculum were taken from some infected citrus fruits with typical green-mold signs, cultured on a potato dextrose agar (PDA) medium at $27^{\circ} \mathrm{C}$ for seven days and preserved $\left(4^{\circ} \mathrm{C}\right)$. The collection of mature spores was done by washing PDA surface using autoclaved distilled $\mathrm{H}_{2} \mathrm{O}$, and then spore suspensions were passaged from a sterilized cotton ball in a funnel to check the hyphae. The spore suspension of $P$. digitatum was counted in a Countess-II FL automatic cell counter (Thermo Fisher Scientific, Waltham, MA) and set at $1 \times 10^{6} \mathrm{CFU} / \mathrm{mL}$ using autoclaved distilled $\mathrm{H}_{2} \mathrm{O}$.

\subsection{In Vitro Evaluation of Antifungal Activity}

2.2.1. Disc Diffusion Assay. The modified method of Bauer-Kirby disk tests was used for measuring zones of the antifungal activities of cinnamaldehyde and its derivatives [31]. Petri dishes (diameter, $90 \mathrm{~mm}$ ) were prepared with a PDA medium (about $15 \mathrm{~mL}$ ) and surface inoculated with the optimal concentration of spore suspensions in sterile water. The sterile Oxford cup (diameter, $8 \mathrm{~mm}$ ) was impregnated with $200 \mu \mathrm{L}$ of six cinnamaldehyde derivatives. The diameters of inhibitory zones around the Oxford cups were measured in mm after $72 \mathrm{~h}$ of culture at $27^{\circ} \mathrm{C}$ under darkness. The six cinnamaldehyde derivatives were judged to be a potential antifungal agent when the diameter of inhibitory zone was larger than $8 \mathrm{~mm}$.

\subsubsection{Measurement of Minimal Inhibitory Concentration} (MIC) and Minimum Fungicidal Concentration (MFC). The MIC and MFC of 4-methoxy CA on the mycelial growth of the tested fungal strains were determined using the agar dilution method described previously [32]. Different concentrations of 4-methoxy CA were mixed with PDA in a proportion of $1: 9$ for obtaining the final concentrations of 0 , $15.6,31.3,62.5,125,250$, and $500 \mu \mathrm{g} / \mathrm{mL}$. The $6 \mathrm{~mm}$-diameter mycelial disks cut from a 7-day-old culture of the tested fungal strains were placed in the centre of each Petri dish and incubated at $27^{\circ} \mathrm{C}$. The MIC and MFC were defined as the lowest concentration of 4 -methoxy CA that $100 \%$ inhibited the mycelial growth of $P$. digitatum after $2^{\text {nd }} \mathrm{d}$ and $6^{\text {th }} \mathrm{d}$ of incubation at $27^{\circ} \mathrm{C}$, respectively [33].

\subsection{Inhibitory Effect of 4-Methoxy CA on Spore Germination.} Serial concentrations $(15.6-250 \mu \mathrm{g} / \mathrm{mL})$ of 4 -methoxy CA were tested for their activity against spore germination inhibitory (SGI), with the absence of 4-methoxy CA serving as a control. The PDB medium amended with 4-methoxy CA was transferred onto a concave slide. $20 \mu \mathrm{L}$ of spore suspension $\left(1 \times 10^{5}\right.$ spores $\left.\cdot \mathrm{mL}^{-1}\right)$ was added. All the inoculated slides were placed on moist filter paper on Petri plates at $27^{\circ} \mathrm{C}$ for $12 \mathrm{~h}$. The spore germination was observed using a reversed biological microscope (Olympus CKX53, Japan). The spores were defined as germinated if the germ tube 
length was equal or exceeded that of the spore [32]. The inhibition of spore germination was calculated using the following formula:

$$
\text { Spore germination inhibition }\left(\text { SGI \%) }=\frac{G c-G t}{G c} \times 100\right. \text {, }
$$

where Gc and Gt are the mean number of germinated spores of control and treated slides, respectively. Four replicates were used per treatment, and the experiment was carried out with two separate times.

2.4. Determination of Membrane Permeability. The determination of extracellular conductivity was carried out using a ST3100c/F electrical conductivity meter (Ohaus Co., Ltd., New Jersey, America). After $48 \mathrm{~h}$ of shake inoculating in $\mathrm{PDB}$ at $27^{\circ} \mathrm{C}, 5.0 \mathrm{~g}$ of the healthy mycelia of $P$. digitatum was resuspended in $100 \mathrm{~mL} \mathrm{PDB}$ with the 4-methoxy CA stock solution to the final concentrations of $1 / 2$ MIC, MIC, 2 MIC, and MFC. The extracellular electric conductivity was determined at $0,30,60,90$, and 120 min of the 4-methoxy CAtreated and control PDB, and expressed as the amount of extracellular conductivity $(\mu \mathrm{s} / \mathrm{cm})$.

2.5. Assay for Intracellular Reducing Sugars. The reducing sugar content of $P$. digitatum mycelia, treated with 4methoxy CA using a range of concentrations (0, MIC, $2 \mathrm{MIC}$, and MFC), was examined through the anthrone colorimetric method [32] with certain minor changes. About $0.5 \mathrm{~g}$ (wet weight) of P. digitatum mycelia of 4-methoxy CAtreated and control PDB groups was collected, and homogenization was done in $8.0 \mathrm{~mL}$ of $\mathrm{dH}_{2} \mathrm{O}$; extracts were taken out through boiling $\mathrm{H}_{2} \mathrm{O}$ bath for quarter of an hour. Afterwards, these isolated mycelial materials were quickly cooled by placing at $25^{\circ} \mathrm{C}$ for $10 \mathrm{~min}$. Different dilutions were prepared using $\mathrm{dH}_{2} \mathrm{O}$, the volumes of these suspensions were raised to $100 \mathrm{~mL}$, and $1.0 \mathrm{~mL}$ of $10 \%(\mathrm{v} / \mathrm{v})$ lead acetate was mixed in it. Keeping this solution for about $15 \mathrm{~min}$ at room temperature, this suspension was filtered by a Buchner funnel after mixing $0.1 \mathrm{~g}$ of crystal violet oxalate in it. Then, $2 \mathrm{~mL}$ of the filtrate was taken out and heated for $5 \mathrm{~min}$ by placing it in boiling water bath after mixing $0.5 \mathrm{~mL}$ of anthrone reagent (BR 9012-76-4, Sinopharm Chemical

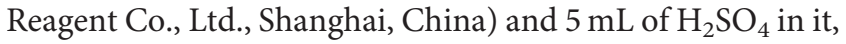
and it was incubated again for further $10 \mathrm{~min}$ in boiling water bath. After cooling this by placing on ice for $10-15 \mathrm{~min}$, the absorbances were measured at $620 \mathrm{~nm}$ to tabulate the levels of reducing sugar from a standard curve using glucose as a standard.

2.6. Statistical Analysis. The data obtained were analyzed by using SPSS 17.0 version (SPSS Inc., USA). The Student's $t$ test was applied to analyze the MGI assay to examine actual levels of reducing sugars. The levels of significantly different values were gone through one-way analysis of variance (ANOVA), and the $p$ value was set at $5 \%$.

\section{Results and Discussion}

3.1. Synthesis of Cinnamaldehyde (CA) Derivatives. Substituted benzaldehyde, $40 \%$ acetaldehyde solution and sodium hydroxide solution were added to the reaction bottle and heated to reflux (Figure 1). The molar ratio of feeding is substituted benzoic aldehyde: acetaldehyde: sodium hydroxide $=1: 1: 1$. After the reaction is completed (TLC tracking the reaction), we cool it to room temperature, add ethyl acetate extraction, combine organic layer, wash with brine, dry anhydrous magnesium sulfate, filter, reduce pressure to recover ethyl acetate solvent, and get crude products. Crude products for column chromatography purification to obtain cinnamaldehyde derivatives a-f and ${ }^{1} \mathrm{H}-\mathrm{NMR}$ identified its constructures (Table 1).

3.2. Antifungal Activity of Cinnamaldehyde (CA) and Its Derivatives. The in vitro antifungal activities of CA along with its six derivatives $(a-f)$ were examined against $P$. digitatum, and their antifungal potential was studied qualitatively by either presence or the absence, and the inhibitory zone sizes. As is shown in Figure 2, the results revealed that 4-methoxy CA had the maximum inhibitory zone $(32.25 \pm 0.35 \mathrm{~mm})$ and the highest antifungal activity, followed by CA $(31.40 \pm 0.57 \mathrm{~mm}), 2$,4-dimethoxy CA $(29.40 \pm 0.57 \mathrm{~mm}), 4$-methyl CA $(21.40 \pm 0.57 \mathrm{~mm})$, 4-chloro CA $(20.50 \pm 0.71 \mathrm{~mm}), 4$-bromo CA $(17.50 \pm 0.71 \mathrm{~mm})$, and 4-nitro CA $(16.80 \pm 0.29 \mathrm{~mm})$.

Among the six CA derivatives, only 4-methoxy CA exhibited more pronounced antifungal activity against $P$. digitatum than CA (Figure 2), and the data in Table 2 ulteriorly confirmed the above result. This finding indicated that 4-methoxy CA could represent a new antifungal agent for inhibiting $P$. digitatum growth. Results of the current study are in agreement with the reports of QuYang et al. [34] who noted that the cinnamaldehyde has strong antifungal activity against $P$. digitatum. In a different study, it was also noted that the incorporation of trans-cinnamaldehyde with poly(lactic acid) and poly(butylene adipate-co-terephthalate) provides better performance as an edible film [35]. Overall, results support the idea suggested by Moosa et al. [36] where the biomaterials were reported as high potent against green and blue mold of citrus fruits.

The MIC and MFC examinations are being applied as one of the most important indexes to access the inhibitory efficiency of antifungal chemicals. The observation was made for $P$. digitatum of mycelial growth using the PDA medium with 4-methoxy CA treatments at $0,15.6,31.3,62.5,125,250$, and $500 \mu \mathrm{g} / \mathrm{mL}$ during the incubation period at $27^{\circ} \mathrm{C}$, and $4-$ methoxy CA treatments at the concentration of $31.3 \mu \mathrm{g} / \mathrm{mL}$ and $125 \mu \mathrm{g} / \mathrm{mL}$ showed $100 \%$ inhibition of $P$. digitatum growth on $2^{\text {nd }}$ and $6^{\text {th }}$ days of incubation, respectively. So, $31.3 \mu \mathrm{g} / \mathrm{mL}$ and $125 \mu \mathrm{g} / \mathrm{mL}$ were the MIC and MFC of 4methoxy CA which inhibit against $P$. digitatum.

3.3. Effect of 4-Methoxy $C A$ on Spore Germination. 4-Methoxy CA significantly $(p<0.05)$ inhibited the spore germination, and the inhibition exerted a dose-dependent 


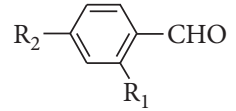

a: $\mathrm{R}_{1}=\mathrm{H} ; \mathrm{R}_{2}=\mathrm{NO}_{2}$
b: $\mathrm{R}_{1}=\mathrm{H} ; \mathrm{R}_{2}=\mathrm{Cl}$

c: $\mathrm{R}_{1}=\mathrm{H} ; \mathrm{R}_{2}=\mathrm{Br}$

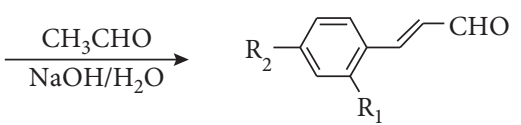

$\mathrm{d}: \mathrm{R}_{1}=\mathrm{H} ; \mathrm{R}_{2}=\mathrm{CH}_{3}$

e: $\mathrm{R}_{1}=\mathrm{H} ; \mathrm{R}_{2}=\mathrm{OCH}_{3}$

$\mathrm{f}: \mathrm{R}_{1}=\mathrm{OCH}_{3} ; \mathrm{R}_{2}=\mathrm{OCH}_{3}$

FIgURE 1: Synthesis of cinnamaldehyde (CA) derivatives.

TABle 1: ${ }^{1} \mathrm{H}-\mathrm{NMR}\left(400 \mathrm{MHz}, \mathrm{CDCl}_{3}\right.$ ) data of cinnamaldehyde (CA) derivatives.

\begin{tabular}{|c|c|c|c|}
\hline Compounds & Name & $\begin{array}{c}\text { Yield } \\
(\%)\end{array}$ & ${ }^{1} \mathrm{H}-\mathrm{NMR}\left(400 \mathrm{MHz}, \mathrm{CDCl}_{3}\right), \delta$ \\
\hline$a$ & 4-Nitro CA & 88.12 & $\begin{array}{c}6.81(\mathrm{dd}, \mathrm{J}=8.0,16.0 \mathrm{~Hz}, 1 \mathrm{H}, \mathrm{CHCHO}), 7.53(\mathrm{~d}, \mathrm{~J}=16.0 \mathrm{~Hz}, 1 \mathrm{H}, \mathrm{PhCH}), 7.72-8.52(\mathrm{~m}, 4 \mathrm{H}, \\
\operatorname{ArH}), 9.68(\mathrm{~d}, \mathrm{~J}=8.0,1 \mathrm{H}, \mathrm{CHO}) .\end{array}$ \\
\hline $\mathrm{b}$ & 4-Chloro CA & 87.32 & $6.67(\mathrm{dd}, \mathrm{J}=7.6,16.0 \mathrm{~Hz}, 1 \mathrm{H}, \mathrm{C} \underline{\mathrm{HCHO}}), 7.39-7.49(\mathrm{~m}, 5 \mathrm{H}, \overline{\mathrm{PhCH}}), 9.68(\mathrm{~d}, \mathrm{~J}=7.6,1 \mathrm{H}, \mathrm{CHO})$. \\
\hline c & 4-Bron & 81.25 & $6.68(\mathrm{dd}, \mathrm{J}=7.6,16.0 \mathrm{~Hz}, 1 \mathrm{H}, \mathrm{C} \underline{\bar{H}} \mathrm{CHO}), 7.40-7.56(\mathrm{~m}, 5 \mathrm{H}, \underline{\mathrm{PhCH}}), 9.69(\mathrm{~d}, \mathrm{~J}=7.6,1 \mathrm{H}, \mathrm{C} \underline{\bar{H}} \mathrm{O})$. \\
\hline $\mathrm{d}$ & 4-Methyl CA & 82.35 & $\begin{array}{c}2.38\left(\mathrm{~s}, 3 \mathrm{H}, \mathrm{CH}_{3}\right), 6.69(\mathrm{dd}, \mathrm{J}=\overline{7.6}, 16.0 \mathrm{~Hz}, 1 \mathrm{H}, \mathrm{CHCHO}), \overline{7.23-7.48}(\mathrm{~m}, 5 \mathrm{H}, \underline{\mathrm{PhCH}}), 9 . \overline{68}(\mathrm{~d}, \\
\mathrm{J}=7.6,1 \mathrm{H}, \overline{\mathrm{CHO}}) .\end{array}$ \\
\hline $\mathrm{e}$ & 4-Methoxy CA & 86.65 & $\begin{array}{c}3.88\left(\mathrm{~s}, 3 \mathrm{H}, \mathrm{OCH}_{3}\right), 6.60(\mathrm{dd}, \mathrm{J}=7.6,16.0 \mathrm{~Hz}, 1 \mathrm{H}, \mathrm{C} \overline{\mathrm{H}} \mathrm{CHO}), 6.93(\mathrm{~d}, \mathrm{~J}=6.4,2 \mathrm{H}, \mathrm{ArH}), 7.42(\mathrm{~d}, \\
\mathrm{J}=7.6,1 \mathrm{H}, \mathrm{PhC} \underline{\mathrm{H}}), 7.52(\mathrm{~d}, \mathrm{~J}=8.8,2 \mathrm{H}, \overline{\mathrm{Ar}} \underline{\mathrm{H}}), 9.64(\mathrm{~d}, \mathrm{~J}=7.6,1 \mathrm{H}, \mathrm{CHO}) .\end{array}$ \\
\hline $\mathrm{f}$ & $\begin{array}{l}\text { 2,4-Dimethoxy } \\
\text { CA }\end{array}$ & 81.23 & $\begin{array}{c}3.91\left(\mathrm{~s}, 6 \mathrm{H}, \mathrm{OCH}_{3}\right), 6.60(\overline{\mathrm{dd}}, \mathrm{J}=7.6,16.0 \mathrm{~Hz}, 1 \mathrm{H}, \mathrm{CHCHO}), 6.85-7.07(\mathrm{~m}, 3 \mathrm{H}, \overline{\mathrm{A}} \mathrm{rH}), 7.40(\mathrm{~d}, \\
\mathrm{J}=16.0,1 \mathrm{H}, \mathrm{PhCH}), 9.64(\mathrm{~d}, \overline{\mathrm{J}}=7.6,1 \mathrm{H}, \mathrm{CHO}) .\end{array}$ \\
\hline
\end{tabular}

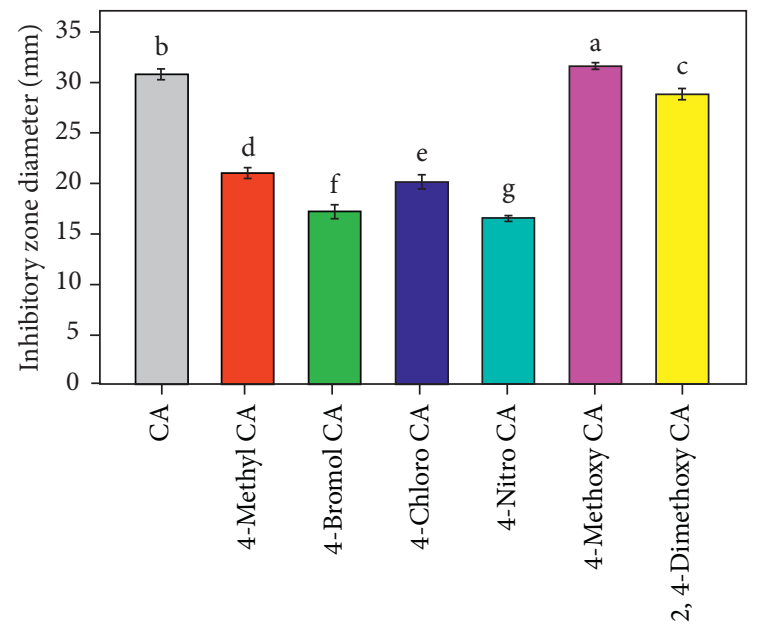

FIGURE 2: The antifungal activity of CA and its derivatives against $P$. digitatum (each compound concentration was $8 \mathrm{mg} / \mathrm{mL}$ ).

fashion (Table 3). Increasing the concentrations of 4methoxy CA, the spore germination decreased significantly. When the concentration reached $15.6 \mu \mathrm{g} / \mathrm{mL}$, the spore germination was inhibited by $27.50 \%$, whereas $250 \mu \mathrm{g} / \mathrm{mL} 4$ methoxy CA treatment roughly inhibited the spore germination, reached an inhibition by $92.87 \%$. A logarithm model $\left(y=2.247+1.501 x, R^{2}=0.92\right)$ was used to describe the relationship between 4-methoxy CA concentrations and SGI after $12 \mathrm{~h}$ of incubation. The half effective concentration $\left(\mathrm{EC}_{50}\right)$ and $95 \%$ effective concentration $\left(\mathrm{EC}_{95}\right)$ values of 4 methoxy CA were calculated to $39 \mu \mathrm{g} / \mathrm{mL}$ and $391 \mu \mathrm{g} / \mathrm{mL}$, respectively (Table 3 ). The results indicate that 4 -methoxy CA significantly inhibited the spore germination of $P$. digitatum in vitro.
TABle 2: Inhibition effects of 4-methoxy CA and CA against P. digitatum.

\begin{tabular}{lcc}
\hline \multirow{2}{*}{ Concentration $(\mathrm{mg} / \mathrm{mL})$} & \multicolumn{2}{c}{ Inhibition zone $(\mathrm{mm})$} \\
& \multicolumn{2}{c}{$0.00 \pm 0.00$} \\
\hline 0 & $20.65 \pm 0.49 \mathrm{a}$ & $19.80 \pm 0.28 \mathrm{~b}$ \\
4 & $27.75 \pm 0.35 \mathrm{a}$ & $26.55 \pm 0.21 \mathrm{~b}$ \\
6 & $29.65 \pm 0.49 \mathrm{a}$ & $28.10 \pm 0.82 \mathrm{~b}$ \\
8 & $32.25 \pm 0.35 \mathrm{a}$ & $31.40 \pm 0.57 \mathrm{~b}$ \\
10 & $32.85 \pm 0.21 \mathrm{a}$ & $31.75 \pm 0.35 \mathrm{~b}$ \\
\hline
\end{tabular}

3.4. Optical Microscopy Observation. The morphology of $P$. digitatum individual hyphae exposed to 4-methoxy CA (0, MIC and MFC) was examined using an optical microscope. The microscopic images exposed the morphological structures of control mycelium found normal having smooth surface (Figure 3). Upon treating with 4-methoxy CA at MIC, the $P$. digitatum mycelium was observed having irregular swellings (Figure 3) and emptied mycelial cells when treated with 4-methoxy CA at MFC, clearly indicated that the rupture of cellular membranes lead to leakage of the cytoplasmic inclusions and death of the cell (Figure 3). Obviously, 4-methoxy CA treatment resulted in damage to $P$. digitatum mycelia.

3.5. Effect of 4-Methoxy CA on Membrane Permeability. The extracellular conductivity of $P$. digitatum suspension treated with a range of concentrations (0, 1/2 MIC, MIC, $2 \mathrm{MIC}$, and $\mathrm{MFC}$ ) of 4-methoxy CA for multiple time $(0-120 \mathrm{~min})$ fashion is shown in Figure 4. Following the different treatment levels, immediately but significant rise in the extracellular conductivity was seen. After about half an 
TABLE 3: Effect of different 4-methoxy CA concentrations on germination of spores of $P$. digitatum after incubation at $27 \pm 1^{\circ} \mathrm{C}$ for $12 \mathrm{~h}$.

\begin{tabular}{lcccc}
\hline Concentrations $(\mu \mathrm{g} / \mathrm{mL})$ & Spore germination & SGI & Toxic regression equation & Effective concentration $(\mathrm{EC}, \mu \mathrm{g} / \mathrm{mL})$ \\
\hline 0 & $90.48 \pm 0.46 \mathrm{a}$ & 0f & & \\
15.6 & $65.60 \pm 0.74 \mathrm{~b}$ & $27.50 \pm 0.65 \mathrm{e}$ & & \\
31.3 & $56.15 \pm 0.82 \mathrm{c}$ & $37.94 \pm 0.75 \mathrm{~d}$ & $y=2.247+1.501 x$ & $\mathrm{EC}_{50}=39(22-43)$ \\
62.5 & $30.00 \pm 0.69 \mathrm{~d}$ & $66.84 \pm 0.47 \mathrm{c}$ & $R^{2}=0.92$ & EC $_{95}=391(210-1415)$ \\
125 & $19.82 \pm 1.10 \mathrm{e}$ & $78.09 \pm 0.42 \mathrm{~b}$ & \\
250 & $6.45 \pm 0.35 \mathrm{f}$ & $92.87 \pm 0.02 \mathrm{a}$ & \\
\hline
\end{tabular}
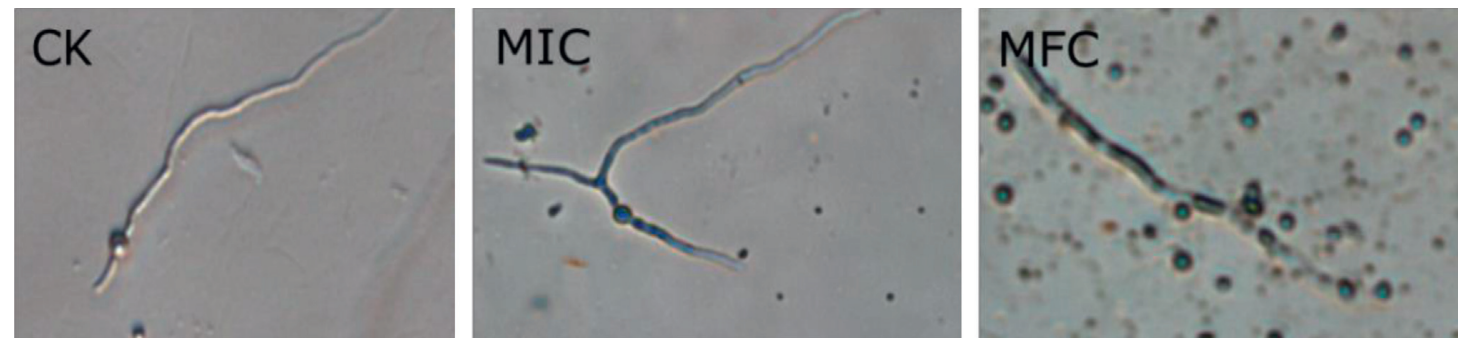

FIGURE 3: Effect of 4-methoxy CA on hyphal morphology of P. digitatum. Control, untreated mycelia; MIC, mycelia treated with 4-methoxy CA at $31.3 \mu \mathrm{g} / \mathrm{mL}$; MFC, mycelia treated with 4-methoxy CA at $125 \mu \mathrm{g} / \mathrm{mL}$.

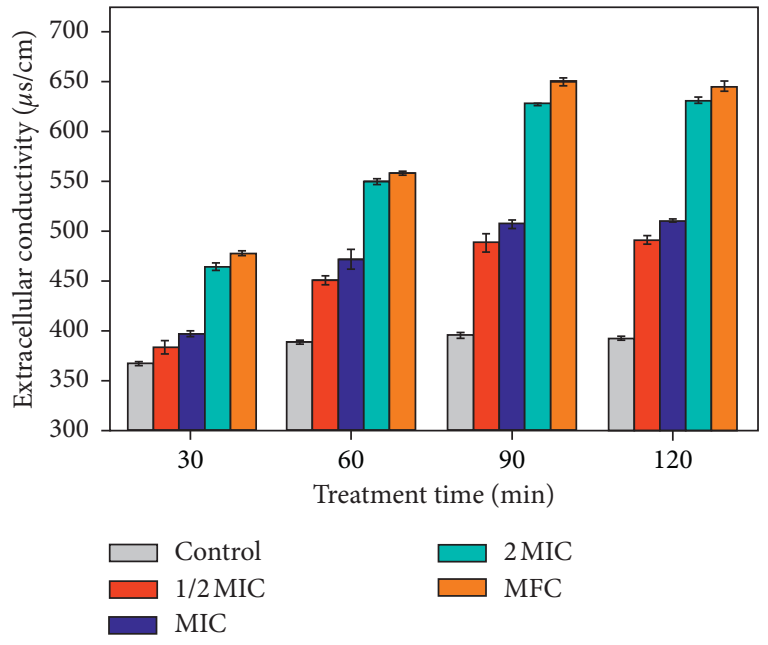

FIGURE 4: Effect of 4-methoxy CA on extracellular conductivity of $P$. digitatum suspensions. Values are mean \pm SE $(n=3)$.

hour of 4-methoxy CA treatment, extracellular conductivity was measured which ranged from $1 / 2 \mathrm{MIC}$ to MFC, 383.0 to $477.3 \mu \mathrm{s} / \mathrm{cm}$, a significant $(p<0.05)$ increase than its respective control $(361 \mu \mathrm{s} / \mathrm{cm})$. The increase in the treatment duration helped a marked increase in the extracellular conductivity. Following $2 \mathrm{~h}$ of treatment, the extracellular conductivity in $P$. digitatum suspensions exposed to 4-methoxy $\mathrm{CA}$ at 1/2 MIC, MIC, $2 \mathrm{MIC}$, and MFC showed a sharp increase $(491.0 \pm 4.4,510.3 \pm 1.5,631.3 \pm 3.1$, and $645.3 \pm 5.0 \mu \mathrm{s} /$ $\mathrm{cm}$ ) demonstrating that using high dose of 4-methoxy CA may lead to significant growth by triggering the accelerated cell disruption in $P$. digitatum suspensions.

3.6. Effect of 4-Methoxy CA on Reducing Sugar Content. In order to assess whether the biosynthesis and production of intracellular inclusions have been damaged after 4-

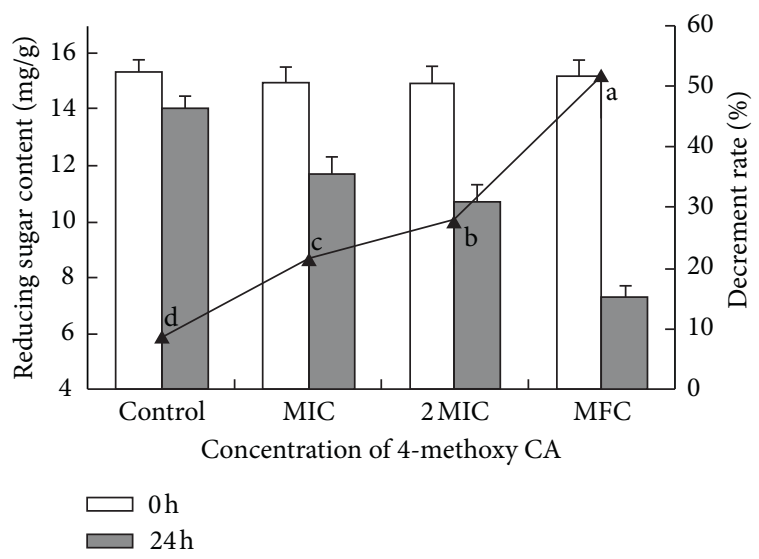

FIgURE 5: Effect of 4-methoxy CA on reducing sugar content of $P$. digitatum mycelia. Values are mean $(n=3) \pm \mathrm{SE}$.

methoxy CA treatment, the level of reducing sugars was examined. The levels of reducing sugars of 4-methoxy CA treated $P$. digitatum mycelia at MIC, 2 MIC, and MFC were $11.67 \pm 0.70 \mathrm{mg} / \mathrm{g}, 10.67 \pm 0.65 \mathrm{mg} / \mathrm{g}$, and $7.33 \pm 0.38 \mathrm{mg} / \mathrm{g}$, respectively, reasonably lower compared with the control group at $24 \mathrm{~h}$ of incubation $(14.03 \pm 0.53 \mathrm{mg} / \mathrm{g}$ ) (Figure 5), which indicated that the biosynthesis and production of reducing sugar content restrained. It is widely accepted that the decrease of reducing sugar content disturbs energy metabolism. In this case, 4-methoxy CA treatment caused the decrease of reducing sugar, being a direct danger to energy supply.

\section{Conclusions}

Cinnamaldehyde and its derivatives bear diverse pharmacological activities. In the current study, we synthesized multiple derivatives of cinnamaldehyde viz. 4-nitro CA, 4chloro CA, 4-bromo CA, 4-methyl CA, 4-methoxy CA, and 
2,4-dimethoxy CA, but 4-methoxy CA showed highest antifungal actions for citrus fruit postharvest rotting fungi Penicillium digitatum (Green mold). Moreover, 4-methoxy $\mathrm{CA}$ reduces the spore germination and growth by damaging the fungal cell membrane, as well as declines the levels of reducing sugars. It appears that 4-methoxy CA is a good antifungal agent and can be used for postharvest storage of citrus fruits.

\section{Data Availability}

All data used to support the findings of this study are included within the paper.

\section{Conflicts of Interest}

The authors declare no conflicts of interest.

\section{Acknowledgments}

This research was funded by the National Natural Science Foundation of China, grant nos. 32060703 and 31760598.

\section{References}

[1] Y. Liu, E. Heying, and S. A. Tanumihardjo, "History, global distribution, and nutritional importance of citrus fruits," Comprehensive Reviews in Food Science and Food Safety, vol. 11, no. 6, pp. 530-545, 2012.

[2] E. Wuryatmo, A. Klieber, and E. S. Scott, "Inhibition of citrus postharvest pathogens by vapor of citral and related compounds in culture," Journal of Agricultural and Food Chemistry, vol. 51, no. 9, pp. 2637-2640, 2003.

[3] S. Tian, R. Torres, A.-R. Ballester, B. Li, L. Vilanova, and L. González-Candelas, "Molecular aspects in pathogen-fruit interactions: virulence and resistance," Postharvest Biology and Technology, vol. 122, pp. 11-21, 2016.

[4] M. Marcet-Houben, A.-R. Ballester, B. de la Fuente et al., "Genome sequence of the necrotrophic fungus Penicillium digitatum, the main postharvest pathogen of citrus," BioMed Central Genomics, vol. 13, no. 1, p. 646, 2012.

[5] M. López-Pérez, A. R. Ballester, and L. González-Candelas, "Identification and functional analysis of Penicillium digitatum genes putatively involved in virulence towards citrus fruit," Molecular Plant Pathology, vol. 16, no. 3, pp. 262-275, 2015.

[6] M. Mari, A. Di Francesco, and P. Bertolini, "Control of fruit postharvest diseases: old issues and innovative approaches," Stewart Postharvest Review, vol. 10, no. 1, pp. 1-4, 2014.

[7] W. Hao, G. Zhong, M. Hu, J. Luo, Q. Weng, and M. Rizwanul-Haq, "Control of citrus postharvest green and blue mold and sour rot by tea saponin combined with imazalil and prochloraz," Postharvest Biology and Technology, vol. 56, no. 1, pp. 39-43, 2010.

[8] Y. Gao, C. Kan, M. Chen et al., "Effects of chitosan-based coatings enriched with cinnamaldehyde on Mandarin fruit cv. Ponkan during room-temperature storage," Coatings, vol. 8, no. 10, p. 372, 2018.

[9] Y. Gao, C. Kan, C. Wan, C. Chen, M. Chen, and J. Chen, "Quality and biochemical changes of navel orange fruits during storage as affected by cinnamaldehyde -chitosan coating," Scientia Horticulturae, vol. 239, pp. 80-86, 2018.
[10] J. Chen, Y. Shen, C. Chen, and C. Wan, "Inhibition of key citrus postharvest fungal strains by plant extracts in vitro and in vivo: a review," Plants, vol. 8, no. 2, p. 26, 2019.

[11] S. Shreaz, W. A. Wani, J. M. Behbehani et al., "Cinnamaldehyde and its derivatives, a novel class of antifungal agents," Fitoterapia, vol. 112, pp. 116-131, 2016.

[12] S.-S. Cheng, J.-Y. Liu, E.-H. Chang, and S.-T. Chang, “Antifungal activity of cinnamaldehyde and eugenol congeners against wood-rot fungi," Bioresource Technology, vol. 99, no. 11, pp. 5145-5149, 2008.

[13] H.-S. Lee and Y.-J. Ahn, "Growth-inhibiting effects of Cinnamomum cassia bark-derived materials on human intestinal bacteria," Journal of Agricultural and Food Chemistry, vol. 46, no. 1, pp. 8-12, 1998.

[14] S.-T. Chang, P.-F. Chen, and S.-C. Chang, "Antibacterial activity of leaf essential oils and their constituents from Cinnamomum osmophloeum," Journal of Ethnopharmacology, vol. 77, no. 1, pp. 123-127, 2001.

[15] S. Shreaz, R. A. Sheikh, B. Rimple, A. A. Hashmi, M. Nikhat, and L. A. Khan, "Anticandidal activity of cinnamaldehyde, its ligand and $\mathrm{Ni}(\mathrm{II})$ complex: effect of increase in ring and side chain," Microbial Pathogenesis, vol. 49, no. 3, pp. 75-82, 2010.

[16] K.-H. Bang, D.-W. Lee, H.-M. Park, and Y.-H. Rhee, "Inhibition of fungal cell wall synthesizing enzymes by transcinnamaldehyde," Bioscience, Biotechnology, and Biochemistry, vol. 64, no. 5, pp. 1061-1063, 2000.

[17] X. Xie, J. Fang, and Y. Xu, "Study of antifungal effect of cinnamaldehyde and citral on Aspergillus flavus," Journal of Food Science, vol. 25, no. 9, pp. 32-34, 2004.

[18] J. Usta, S. Kreydiyyeh, P. Barnabe, Y. Bou-Moughlabay, and H. Nakkash-Chmaisse, "Comparative study on the effect of cinnamon and clove extracts and their main components on different types of ATPases," Human \& Experimental Toxicology, vol. 22, no. 7, pp. 355-362, 2003.

[19] T.-B. Yen and S.-T. Chang, "Synergistic effects of cinnamaldehyde in combination with eugenol against wood decay fungi," Bioresource Technology, vol. 99, no. 1, pp. 232-236, 2008.

[20] S. Yang, "Progress in the synthesis of cinnamaldehyde," Shandong Chemical Industry, vol. 3, 2013.

[21] H. Wang, Y. Haijian, L. Shujun, L. Zhuo, J. Mingyue, and H. Jiafa, "Activity prediction of Schiff base compounds using improved QSAR models of cinnamaldehyde analogues and derivatives," Bioresource Technology, vol. 10, no. 4, pp. 7921$7935,2015$.

[22] L. Xue-mei, "Synthesis of cinnamaldehyde," Journal of Qufu Normal University (Natural Science), vol. 42, no. 2, pp. 96-98, 2005.

[23] Y. Zhang, S. Li, and X. Kong, "Relationship between antimold activity and molecular structure of cinnamaldehyde analogues," Bioorganic \& Medicinal Chemistry Letters, vol. 23, no. 5, pp. 1358-1364, 2013.

[24] Y. Cui, G. Liang, Y.-H. Hu et al., "Alpha-substituted derivatives of cinnamaldehyde as tyrosinase inhibitors: inhibitory mechanism and molecular analysis," Journal of Agricultural and Food Chemistry, vol. 63, no. 2, pp. 716-722, 2015.

[25] Y. Akimoto, S. Nito, and G. Urakubo, "Studies on the metabolic fate of $\alpha$-bromocinnamaldehyde (an anti-fungal agent) in rat," Eisei Kagaku, vol. 34, no. 4, pp. 303-312, 1988.

[26] T. H. Kang, E. I. Hwang, B. S. Yun et al., "Inhibition of chitin synthases and antifungal activities by $2^{\prime}$-benzoyloxycinnamaldehyde from pleuropterus ciliinervis and its derivatives," Biological \& Pharmaceutical Bulletin, vol. 30, no. 3, pp. 598-602, 2007. 
[27] Q.-Y. Wei, J.-J. Xiong, H. Jiang, C. Zhang, and W. Ye, "The antimicrobial activities of the cinnamaldehyde adducts with amino acids," International Journal of Food Microbiology, vol. 150, no. 2-3, pp. 164-170, 2011

[28] R. Bhatia, S. Shreaz, N. Khan et al., "Proton pumping ATPase mediated fungicidal activity of two essential oil components," Journal of Basic Microbiology, vol. 52, no. 5, pp. 504-512, 2012.

[29] S. Ishida, A. Matsuda, Y. Kawamura, and K. Yamanaka, "Antifungal agent. I. Antibacterial and antifungal activities in vitro of several organic compounds. II. Antibacterial and antifungal activities of cinnamaldehyde derivatives. III. Antibacterial and antifungal activities of $\alpha$-bromocinnamaldehyde derivatives," Chemotherapy, vol. 8, pp. 146-159, 1960.

[30] M. E. I. Badawy and E. I. Rabea, "Synthesis and structureactivity relationship of $\mathrm{N}$-(cinnamyl) chitosan analogs as antimicrobial agents," International Journal of Biological Macromolecules, vol. 57, pp. 185-192, 2013.

[31] A. L. Barry, M. B. Coyle, C. Thornsberry, E. H. Gerlach, and R. W. Hawkinson, "Methods of measuring zones of inhibition with the Bauer-Kirby disk susceptibility test," Journal of Clinical Microbiology, vol. 10, no. 6, pp. 885-889, 1979.

[32] C. Chen, W. Qi, X. Peng, J. Chen, and C. Wan, "Inhibitory effect of 7-demethoxytylophorine on Penicillium italicum and its possible mechanism," Microorganisms, vol. 7, no. 2, p. 36, 2019.

[33] C. Chen, C. Wan, X. Peng, and J. Chen, "A flavonone pinocembroside inhibits Penicillium italicum growth and blue mold development in "Newhall" navel oranges by targeting membrane damage mechanism," Pesticide Biochemistry and Physiology, vol. 165, Article ID 104505, 2020.

[34] Q. QuYang and R. O. Okwong, Y. Chen, N. Tao, " Synergistic activity of cinnamaldehyde and citronellal against green mold in citrus fruit," Postharvest Biology and Technology, vol. 162, Article ID 111095, 2020.

[35] A. Srisa and N. Harnkarnsujarit, "Antifungal films from transcinnamaldehyde incorporated poly(lactic acid) and poly(butylene adipate-co-terephthalate) for bread packaging," Food Chemistry, vol. 333, Article ID 127537, 2020.

[36] A. Moosa, S. T. Sahi, S. A. Khan, and A. U. Malik, "Salicylic acid and jasmonic acid can suppress green and blue moulds of citrus fruit and induce the activity of polyphenol oxidase and peroxidase," Folia Horticulturae, vol. 31, no. 1, pp. 195-204, 2019. 